*Note: this is the penultimate draft; please cite from the published version.

\title{
On Wittgenstein's Notion of a Surveyable Representation: Rituals, Aesthetics, and Aspect-Perception
}

\author{
Nir Ben-Moshe (nir@illinois.edu) \\ University of Illinois at Urbana-Champaign
}

\begin{abstract}
I demonstrate that analogies, both explicit and implicit, between Wittgenstein's discussions of rituals, aesthetics, and aspect-perception, have important payoffs in terms of understanding his notion of a "surveyable representation" (übersichtliche Darstellung) as it applies to phenomena that are not exclusively grammatical in nature. In particular, I argue that a surveyable representation of certain anthropological and aesthetic facts allows us to see, qua form of aspect-perception, internal relations and formal connections, so that the inner nature of a ritual or the solution of an aesthetic puzzle is exhibited. This particular form of seeing both explains why Wittgenstein thought that hypothetical explanations about the origins of a ritual are irrelevant to appreciating its meaning and elucidates his understanding of rituals, which involves seeing "internal relations" and "formal connections." The upshots of the account for work in anthropology are discussed.
\end{abstract}

Keywords: Aesthetics; Anthropology; Aspect-Perception; Perspicuous Representation; Surveyable Representation; Wittgenstein 


\section{Introduction}

Consider the following two puzzling views that Wittgenstein advances in his 'Remarks on Frazer's Golden Bough." First, he seems to argue that knowledge of the origins of a ritual is irrelevant to appreciating its meaning. Second, he argues that the meaning of a given ritual is both part of the ritual itself and ascribed from one's own feelings and thoughts. Both of these views require an explanation, since: (a) it seems that the meaning of most rituals can only be elucidated by reference to their origins, so that the question of what a ritual means cannot be entirely segregated from its development; (b) it is not clear how we should reconcile the fact that the meaning of a given ritual is both dependent on and independent of spectators, especially given Wittgenstein's talk of perceiving "internal relations" and "formal connections" in his discussion of Frazer. My point of entry is Moore's observation that Wittgenstein's “discussion of Aesthetics [...] was mingled in a curious way with criticism of assumptions which he said were constantly made by Frazer in the Golden Bough" (MWL I 312). ${ }^{1}$ A thread running through these remarks is the distinction between hypothetical explanations and a synopsis of the facts, suggestive of a view according to which the value of both projects lies in a certain type of synopsis they provide of the facts in question. My aim in this paper is to demonstrate that analogies, both explicit and implicit, between Wittgenstein's discussions of rituals, aesthetics, and aspect-perception, have important payoffs in terms of understanding his notion of a "surveyable representation” (übersichtliche Darstellung) perhaps most well-known from Wittgenstein's meta-philosophy, where its subject matter is

\footnotetext{
1 This quote summarizes Moore's own impressions from Wittgenstein's Cambridge lectures. The verbatim text of Moore's notes, published recently and referenced as MWL II (see "references" for a full list of abbreviations), strengthens this claim: for example, on May $26^{\text {th }} 1933$, Wittgenstein intertwines remarks on aesthetics with remarks about Frazer's Golden Bough (MWL II 356-357). In these lectures, Wittgenstein also notes similarities between aesthetics, Frazer's Golden Bough, and psychoanalysis, but I will not be discussing the latter in the current paper. I discuss Wittgenstein's notion of a surveyable representation in relation to psychoanalysis in Ben-Moshe (forthcoming).

2 The German "übersichtliche Darstellung," which used to be translated as "perspicuous representation," is now translated as "surveyable representation" in the latest (revised fourth) edition of Philosophical Investigations.
} 
grammatical—as it applies to phenomena that are not exclusively grammatical in nature. ${ }^{3}$ In particular, I will argue that a surveyable representation of certain anthropological and aesthetic facts allows us to see, qua form of aspect-perception, internal relations and formal connections, so that the inner nature of a ritual or the solution of an aesthetic puzzle is exhibited. This particular form of seeing both explains why Wittgenstein thought that hypothetical explanations about the origins of a ritual are irrelevant to appreciating its meaning and elucidates his understanding of rituals, which involves seeing "internal relations" and "formal connections." Regarding the former, I will argue that Wittgenstein's concern is not only methodological (a matter of where one looks in examining the phenomena), but also epistemological (a concern with a kind of seeing versus a kind of interpreting), a distinction brought out by attention to Wittgenstein's remarks on aspectperception. I conclude by briefly discussing the upshots of the account for work in anthropology.

\section{From Philosophical Methodology to Rituals}

The notion of a "surveyable representation" is central to Wittgenstein's philosophical methodology, which is most succinctly summarized in Philosophical Investigations:

[O]ur considerations must not be scientific ones. [...] And we may not advance any kind of theory. There must not be anything hypothetical in our considerations. All explanation must disappear, and description alone must take its place. And this description gets its light - that is to say, its purpose - from the philosophical problems. These are, of course, not empirical problems; but they are solved through an insight into the workings of our language, and that in such a way that these workings are recognized — despite an urge to misunderstand them. The problems are solved, not by coming up with new discoveries, but by assembling what we have long been familiar with. [PI §109]

\footnotetext{
${ }^{3}$ I do not wish to imply that the phenomena in question are, in some strong sense, non-linguistic or non-conceptual. Rather, contrary to philosophical investigations, these phenomena are not exclusively linguistic or conceptual.
} 
Philosophical investigations, which are "grammatical" or "conceptual" (PI §90; Z §458), do not make use of hypothetical explanations in order to solve empirical problems, because "philosophy just puts everything before us, and neither explains nor deduces anything. — Since everything lies open to view, there is nothing to explain" (PI §126). This methodology has both a positive and a negative aspect. On the positive side, Wittgenstein argued that "the task of philosophy" is "to clarify the use of our language" (PG 115). On the negative side, instead of trying to solve the problems of philosophy, the methodology "sheds light on our problem by clearing misunderstandings away," primarily misunderstandings "concerning the use of words" (PI §90). When this happens, philosophical problems dissipate of themselves (PI §119). Indeed, the negative and positive tasks of Wittgenstein's philosophical methodology are intertwined, for aiming at "complete clarity $[\ldots]$ simply means that the philosophical problems should completely disappear" (PI §133). ${ }^{4}$ This clarity is attained via a "surveyable representation" (übersichtliche Darstellung):

A main source of our failure to understand is that we don't have an overview of the use of our words. - Our grammar is deficient in surveyability. - A surveyable representation produces precisely that kind of understanding which consists in 'seeing connections'. Hence the importance of finding and inventing intermediate links. The concept of a surveyable representation is of fundamental significance for us. It characterizes the way we represent things, how we look at matters. (Is this a 'Weltanschauung'?) [PI §122]

A surveyable representation helps us understand the "essence of language"-construed as "something that already lies open to view" and not as "something that lies beneath the surface"which "becomes surveyable through a process of ordering" (PI §92). More specifically, it helps us to "establish an order in our knowledge of the use of language" by emphasizing "distinctions which our ordinary forms of language easily make us overlook” (PI §132). Interpretations vary regarding

\footnotetext{
${ }^{4}$ For an excellent discussion of the negative and positive sides of Wittgenstein's philosophical methodology and the close relation between them, see Kenny (1982).
} 
the workings of a surveyable representation. According to a "Bird's-eye View Model," such a representation is "a presentation or arrangement of grammatical rules which can be taken in as a whole," much in the same way that one can attain a bird's-eye view of a city by looking down on it from a height (Baker 2004: 25-26). According to the more recent and modest "Neglected Aspects Model," a surveyable representation merely brings "hitherto unnoticed aspects of things to a person's awareness," that is, it gets him "to see things differently" (ibid.: 35 ). ${ }^{5}$

Baker (2004: 42) notes that a surveyable representation can have non-grammatical subjectmatters, such as "the morphology of plants, the classification of animals, religious ceremonies, or magical rites," and so it "is not a pleonasm to speak of 'a [surveyable] representation of grammar'." The most detailed discussion of a surveyable representation that is not "of grammar" occurs in the "Remarks on Frazer's Golden Bough." In these remarks, Wittgenstein argues that "the very idea of wanting to explain a practice [...] seems wrong" and criticizes Frazer's attempts at providing causal-hypothetical explanations about the origins of practices, arguing that the impression that a practice has on us is not due to a hypothesis about its origins (GB $119 \& 123$ ). In place of the explanation, what we are really interested in is a description: "[O]ne must only correctly piece together what one knows, without adding anything, and the satisfaction being sought through the explanation follows of itself [...] Here one can describe and say: this is what human life is like" (GB 121; see also MWL II 331 \& 357). This methodology allows one "to see the data in their relation to one another and to embrace them in a general picture without putting it in the form of

\footnotetext{
${ }^{5}$ The "Bird's-eye View Model," is perhaps most associated with Baker and Hacker (2005: 326-334). See Martin
} (2016) for an excellent discussion of the difference between these models. 
an hypothesis about temporal development" (GB 131). The general picture is a "surveyable representation," as Wittgenstein asserts in a passage that served as the basis for PI $\S 122^{6}$ :

"And so the chorus points to a secret law" one feels like saying to Frazer's collection of facts. I can represent this law, this idea, by means of an evolutionary hypothesis, or also, analogously to the schema of a plant, ${ }^{[7]}$ by means of the schema of a religious ceremony, but also by means of the arrangement of its factual content alone, in a 'perspicuous' [surveyable] representation [in einer 'übersichtlichen' Darstellung]. The concept of perspicuous representation is of fundamental importance for us. It denotes the form of our representation, the way we see things. (A kind of 'World-view' [...].) This perspicuous representation brings about the understanding which consists precisely in the fact that we "see the connections". Hence the importance of finding connecting links. ${ }^{[8]}$ [GB 133]

Importantly, Wittgenstein notes that the "connecting links" do nothing more than direct our attention to "the similarity, the relatedness, of the facts," in the same way that one might illustrate "an internal relation of a circle to an ellipse by gradually converting an ellipse into a circle"; however, Wittgenstein continues, "not in order to assert that a certain ellipse actually, historically, had originated from a circle (evolutionary hypothesis), but only in order to sharpen our eye for a formal connection" (GB 133).

The clearest example that Wittgenstein provides of the relevant facts and of what we see when using a surveyable representation of rituals occurs in his discussion of the Beltane Festival. This Gaelic fire festival, which lasted into the eighteenth century, was celebrated on May Day. During this festival, participants would perform fire-centered rituals which were intended, among other

\footnotetext{
${ }^{6}$ As Hacker (2001: 75) notes, PI $\$ 122$, the section about a surveyable representation, was taken from remarks that Wittgenstein wrote about The Golden Bough in 1930-1931 and transformed into a comment on philosophical method.

${ }^{7}$ This is a reference to Goethe's notion of the primal plant (Urpflanze) and his attempt to describe parts of plants in reference to an archetypal leaf-form. Indeed, in his Cambridge lectures, Wittgenstein discusses Goethe's Metamorphose der Pflanzen in relation to Frazer's treatment of the Beltane Festival (MWL II 352). For an excellent discussion of Goethe's influence on Wittgenstein, see Klagge (2003).

${ }^{8}$ The English phrase "connecting links" is the translation for the German term "Zwischenglieder". This is also the German term which appeared in PI $§ 122$ and which was translated in that case as "intermediate links."
} 
things, to preserve their livestock and yield a plentiful harvest (Frazer 1994: 716-722). In one ritual a "pretended victim was seized, and a show made of throwing him into the flames, and for some time afterwards people affected to speak of him as dead," which, according to Frazer, is "a mitigated survival of an older custom of actually burning [people]" (ibid., 744). Indeed, Frazer argues that "the traces of human sacrifices at [the Beltane fires] were particularly clear and unequivocal" (ibid., 716). Wittgenstein, for his part, cautions that (a) the meaning of the practice does not depend on its history being a certain way, for perhaps it was not like this at all, and (b) even if we are provided with evidence regarding the prehistoric origin of the practice, it might be the case that nothing of the original meanings remains in the practice in its present day form (GB 145-147, see also MWL II 326, 330-331, 343). Rather, he argues as follows regarding the practice's meaning:

The question is: does the sinister, as we may call it, attach to the practice of the Beltane Festival in itself, as it was carried on one hundred years ago, or is the Festival sinister only if the hypothesis of its origin turns out to be true? I believe it is clearly the inner nature of the modern practice itself which seems sinister to us, and the familiar facts of human sacrifice only indicate the lines along which we should view the practice. When I speak of the inner nature of the practice, I mean all circumstances under which it is carried out and which are not included in a report of such a festival, since they consist not so much in specific actions which characterize the festival as in what one might call the spirit of the festival; such things as would be included in one's description, for example, of the kind of people who take part in it, their behavior at other times, that is, their character; the kind of games which they otherwise play. And one would then see that the sinister quality lies in the character of these people themselves. [GB 143-145]

As this discussion suggests, the facts of interest include "the kind of people who take part in it, their behavior at other times, that is, their character; the kind of games which they otherwise play." Moreover, when Wittgenstein discusses Goethe's idea of the "primal plant" as providing a "synoptic presentation," he concludes by noting, in regards to his own philosophical project: "we situate a linguistic form in its surroundings, we see the grammar of our language against a 
background of similar and related games" (VW 311). If we draw the analogy to Wittgenstein's discussion of Frazer, a given practice should be seen against a background of similar and related practices: "What satisfies my puzzlement about Beltane, is $[\ldots]$ simply describing lots of things more or less like Beltane" (MWL II 352). When we see the relatedness of these facts, we perceive "the inner nature of the modern practice itself," its meaning or meanings, without reference to a hypothesis about its origins; or, as Wittgenstein puts it eloquently elsewhere, a ritual can have "its own complex of feelings without being connected with an ancient practice" (AWL 33).

Nevertheless, two crucial questions remain unanswered. First, why would Wittgenstein insist that knowledge of the origins of a practice is not relevant to appreciating the "inner nature" of the practice? Indeed, it seems natural to assume that in so far as certain meanings are attached to a practice, causal-hypothetical explanations about the origins of that practice would shed light on those meanings. As Cioffi (1998a: 185) asks: "[C]an the question of what a ritual means be entirely segregated from an account of its development? Does the Mass, for example, have a meaning independent of how it developed? Aren't there aspects of most rituals whose meaning can only be elucidated by reference to their history?" Second, what exactly is perceived when we perceive the "inner nature" of the practice, and how do we perceive it? This question is especially vexing given a tension in Wittgenstein's remarks. On the one hand, we perceive something that is objectively part of the facts pertaining to the practice: this is evident in Wittgenstein's talk of "the inner nature of the modern practice itself," as well as in his talk of "internal relations" and "formal connections" in connection with the ellipse-circle analogy. On the other hand, Wittgenstein goes to great lengths to emphasize a subjective component. For example, he argues that whatever connections one discerns between the components of the practice in question, the account would not be complete without "that which brings this picture into connection with our own feelings and thoughts [and] 
gives the account its depth" (GB 143). ${ }^{9}$ This tension is even more striking if we focus on the explanation for the sinister nature of a ritual such as the Beltane festival: while according to the end of the block quote above, "the sinister quality lies in the character of these people [who take part in the practice] themselves," Wittgenstein also argues that it is we who ascribe it from our own experiences. In particular, he asks: "[H]ow is it that in general human sacrifice is so deep and sinister? For is it only the suffering of the victim that makes this impression on us?" He answers that this cannot be the case, since "there are illnesses of all kinds which are connected with just as much suffering, nevertheless they do not call forth this impression. No, the deep and the sinister do not become apparent merely by our coming to know the history of the external action, rather it is we who ascribe them from an inner experience" (GB 147). Therefore, the second question I posed above can be reformulated as follows: how should we reconcile the fact that the meaning of a given ritual is both dependent on and independent of spectators? ${ }^{10}$

These questions bear on the workings of a surveyable representation of rituals. On the face of it, a surveyable representation of rituals has both positive and negative dimensions that parallel, in part, Wittgenstein's philosophical methodology. On the positive side, this representation helps us attain greater clarity and understanding by seeing the inner nature of a ritual. On the negative side, the representation clears away misunderstanding in so far as it shows that we are confused in trying to advance causal-hypothetical explanations about the ritual's inner nature. However, closer inspection leads to the following worries. If we endorse the "Bird's-eye View Model," then a surveyable representation of rituals might be understood as providing "a sort of stamp album," as

\footnotetext{
${ }^{9}$ Indeed, Wittgenstein argues that Frazer's historical explanations also ultimately appeal to a tendency in ourselves: their apparent explanatory power is not in the alleged historical roots of the ritual which they invoke, but rather in the connection of the phenomenon in question to us, to our psychology and sensibilities (GB 127, 137-139, 147).

${ }^{10}$ A version of the tension between the objective and subjective components in Wittgenstein's remarks is noted by Cioffi (1998b: 81-83), who argues that Wittgenstein might not be aware of their distinctiveness, especially since he does not signal a clear transition from one to the other. One of my aims in what follows is to resolve this tension.
} 
Margalit (1992: 308) puts it, in the sense that "the ritual ceremonies should be interpreted as the stamps in an album, enabling the collector to clarify their similarities and differences." However, as Clack (2017: 634) argues, thus understood, it is far from obvious that Wittgenstein's framework of surveyable representation differs substantially from Frazer's approach, for, "once stripped of its theories, [...] The Golden Bough is itself akin to a 'stamp album' of rituals, grouping ceremonies thematically and enabling readers to survey similarities and differences." For example, Frazer (1994: 721-722) concludes his discussion of the Beltane festival by discussing fire festivals in Sweden and Bohemia. If we endorse the "Neglected Aspects Model," then, as Clack (2017: 633634) notes, we might want to say that certain aspects of rituals are neglected in Frazer's account, and so Wittgenstein's methodology is aimed at dispelling any confusion that is the result of this neglect by bringing a ritual into connection with pertinent phenomena. One could argue that the subjective dimension of the account, which pertains to our feelings and thoughts, constitutes the phenomena in question. ${ }^{11}$ Indeed, apart from the aforementioned examples, Wittgenstein notes the similarity between burning an effigy and our practice of kissing the picture of one's beloved (GB 123). And, more generally, when the phenomenon of interest "is brought into connection with an instinct which I myself possess, this is precisely the explanation wished for" (GB 139). Presumably, this thought leads Clack $(2017,634-635)$ to conclude that this second alternative entails that fieldwork and empirical inquiry are not needed when considering rituals, which makes the risk of misunderstanding great, since focusing on our own behavior tells us little about the

\footnotetext{
${ }^{11}$ Some commentators emphasize this aspect. For example, Cioffi [1998c: 180] argues that "the predominant value of Wittgenstein's remarks [on rituals] is not their contribution to the explanatory tasks of anthropology or pre-history but ... the light they shed on our relation to exotic practices." McGuiness [2002: 231-2] notes that "understanding the ritual of a primitive people involves bringing in an inclination we ourselves feel." He adds that "this is nearly always possible: it is as if we have already in our minds the principle underlying the whole diversity of primitive usages." Rhees [1971: 21] argues that "we need not go in search of new facts, nor conjecture them, to understand how there came to be such forms of magic and of ritual"; rather, "all that we need for this is with us in our language, in our ways of thought and feeling."
} 
motivations and expectations of those engaged in the ritual. Put differently, according to the first alternative, the anthropologist was already (more or less) doing what Wittgenstein claims that she ought to do, while according to second alternative, there is not much for the anthropologist to do.

\section{From Aesthetics to Aspect-Perception}

I believe that an examination of Wittgenstein's views on aesthetics and "aspect-perception" can shed light on the aforementioned questions. The comparison between rituals and aesthetics is warranted given analogies that Wittgenstein himself made: in addition to my remarks in the introduction, Moore records that when Wittgenstein discussed Frazer's Golden Bough, he said in connection with the "Beltane Festival" that "in this case you can observe the same thing being puzzling, as in an aesthetic question. You ask: Why does this thing impress us so much?” (MWL II 343). Moreover, while he does not use the term "surveyable representation" in connection with his discussion of aesthetics, Wittgenstein does mention a "resemblance between a philosophical investigation" and "one in aesthetics" (CV 29e), in both of which an "answer to a puzzle is to make a synopsis possible" (MWL II 358). Indeed, Wittgenstein's remarks on aesthetics resemble those on Frazer's Golden Bough (and those on his philosophical methodology), and thus there is good reason to assume that we are entitled to talk of a surveyable representation in aesthetics. In particular, in several lectures and conversations, he argues against the idea of a "science" of aesthetics and clarifies that aesthetics is not a branch of psychology and has nothing to do with psychological experiments. This is so because, while in psychology we are interested in causal connections, the aesthetic puzzle we feel when asked what makes something beautiful is not removed by providing causal-hypothetical explanations about, for example, mechanisms in the brain or general psychological laws. More generally, Wittgenstein claims that in aesthetics one 
should reject any form of explanation, hypothesis, or theory; rather, aesthetics is "descriptive" in nature (LC 11, 17, \& 20; AWL 38-39; MWL II 342 \& 357; WVC 116). Aesthetic descriptions involve "certain comparisons-grouping together of certain cases," for example, "by an arrangement of certain musical figures, comparing their effect on us," which allows us "to solve aesthetic puzzlements" (LC $20 \& 29$ ). Thus, by showing a person a lot of pieces by artist X and drawing her attention to certain features, including pertinent comparisons between artist $\mathrm{X}$ and artist Y (MWL II 350-351) —in this passage, Wittgenstein discusses the example of Brahms and comparing Brahms to Keller — she sees the aesthetic solution: "To tell a person 'This is the climax' is like saying 'This is the man in the puzzle picture'. Our attention is drawn to a certain feature, and from that point forward we see that feature" (AWL 38-39). Wittgenstein calls the descriptions in question "reasons" and describes them as a form of "justification" (MWL II 350-351). Aesthetic reasons are not subjective interpretations of a work of art - they are not about a given spectator's subjective impressions or her feelings of agreeableness or satisfaction (MWL II 340-350) - but rather aid us in perceiving the meaning of a work of art, in understanding "what it all means"” (PI §527), much in the same way that we "hear[...] a word as having this meaning" (PI §534).

Wittgenstein's mention of "internal relations" in connection with the ellipse-circle analogy in his remarks on Frazer resonate with the use of this term in his discussion of aspect-perception (PPF §247). However, is it his discussion of aesthetics that makes for an even more compelling comparison to aspect-perception. First, Wittgenstein notes aspect-perception's resemblance to "conversation on aesthetic matters," where we tend to say: "You have to see it like this, this is how it is meant" (PPF §178). Indeed, in his discussion of aspect-perception, he once again uses the example of "suddenly see[ing] the solution of a puzzle-picture" (PPF §131). Second, when arguing that aesthetics does not pertain to agreeableness, Wittgenstein provides the following example: 
"That a sorrowful face becomes more sorrowful as the mouth turns downward is not a statement of psychology" (AWL 38). If we understand this claim as one about noticing a relation between two faces - the sorrowful and the more sorrowful face-we will appreciate that it is reminiscent of the following claim: "I observe a face, and then suddenly notice its likeness to another. I see that it has not changed; and yet I see it differently. I call this experience "noticing an aspect"" (PPF $\S 113$; see also RPP I §316). ${ }^{12}$ The comparison to aspect-perception is illuminating because of the nature of this type of perception. When we perceive certain things in their relevant aspects, "we are not asking ourselves what are the causes and what produces this impression," since "our problem is not a causal but a conceptual one" (PPF $§ 170 \& 183)$. The experience of "seeing an aspect" is not an interpretation of what is seen, for (a) "to interpret is to think, to do something; seeing is a state" and (b) "when we interpret, we form hypotheses, which may prove false" (PPF $\S \S 248-249)$. Interpretation would be required in the case of knowledge of an aspect, of "knowing what [a picture] is supposed to represent," for example, "when someone treats the picture as a working drawing, reads it like a blueprint” (PPF $\S 169$ \& 192). But reading a picture like a blueprint, and so having knowledge of an aspect, is generally not our attitude towards a picture. Rather, we immediately see the picture in a particular way (PPF §169), "we view the photograph, the picture on our wall, as the very object (the man, landscape, and so on) represented in it" (PPF §197). For example, we see a man with a moustache in a portrait and do not just read off of it information about the visual appearance of the man, such as the fact that he has a moustache (Schroeder 2010: 354). ${ }^{13}$ As Gilead Bar-Elli (2006: 235) puts it, "we see the picture as a picture of

\footnotetext{
${ }^{12}$ When he discusses the Beltane Festival, Wittgenstein also talks of "a multiplicity of faces with common features which continually emerges here and there" and adds that "one would like to draw lines connecting these common ingredients." (GB 143)

${ }^{13}$ See also Mulhall (1990: 6-34), although, contrary to Mulhall, I will remain neutral regarding the question of whether or not aspect-perception is a ubiquitous phenomenon.
} 
so and so, not just interpret it or know it, or regard it to be so. We see the so and so in the picture". Aspect-perception is an experience-we "experience a comparison" in the sense of "seeing, hearing this as a variant of that" (RPP I $\$ 317 \& \S 508)$ - but one in which we perceive, to return to my initial point, "an internal relation between [the object of interest] and other objects" (PPF $\S 247)$, thereby appreciating features of the object of interest. ${ }^{14}$

If we return to Wittgenstein's remarks on Frazer, we will appreciate that what is at stake is not knowledge about what the ritual is supposed to represent, which would be an act of interpretation that may require causal-hypothetical explanations about the ritual's origins. Rather than reading the ritual like a blueprint, we are to see the ritual as the very objects represented in it, thus perceiving the ritual's meaning, which leaves an impression on us akin to seeing the solution in a work of art. This is the reason that Wittgenstein writes that the impression that a practice has on us is not due to a hypothesis about its origins, but rather arises from the "material" which is placed before our eyes and "which leads to this hypothesis" (GB 149). These observations have the following upshot. One might think that the answer to the question of why Wittgenstein insists that knowledge of the origins of a practice is irrelevant to appreciating its meaning is methodological in nature: Explaining aesthetic phenomena by formulating causal hypotheses about people's likes and dislikes reduces the phenomenon of interest-namely, the aesthetic meanings and the reasons for seeing them—-to something else. Likewise, explaining certain rituals

\footnotetext{
${ }^{14}$ I understand aspect-perception and internal relations as involving an objective feature of what is seen. Here I am following Bar-Elli (2006: 247), who develops this Wittgensteinian position and applies it to musical understanding qua understanding that "results from our ability to 'hear the aspect in the notes,' very much like our ability to 'see objects in the (lines of the) drawing'," thus "reveal[ing] what Wittgenstein referred to by [an] 'internal relation'." I am thus disagreeing with, for example, William Day (2017: 15-19), who argues that, in contrast to Jastrow's duckrabbit, talk of "internal relations" in connection with rituals and aesthetics is "a figure of speech" and is not meant to denote "a connection that is established or grounded by anything beyond the experience of connection itself." It is not obvious how this type of account can provide a "justification" that "consists in appealing to an independent authority" (PI §265), for that would presumably require shared "conceptual or grammatical structures" (Mulhall 1990: 131).
} 
by formulating causal hypotheses about the origins of these rituals reduces the phenomenon of interest - namely, the meanings of the practice and the reasons for seeing them - to something else. In other words, one methodology is needed for understanding the ritual's origins (causalhypothetical explanations) and a different methodology is needed for ascertaining its meaning (surveyable representation). ${ }^{15}$ However, a mere appeal to two different methodologies might seem an arbitrary and uninformative distinction, especially if anthropologists already (more or less) do what the "Bird's-eye View Model" of a surveyable representation asks of them. The discussion above suggests that Wittgenstein had another reason, epistemological in nature, for downplaying the role of causal-hypothetical explanations about the ritual's origins. In particular, there are two distinct epistemic states that one can inhabit in regards to the practice: knowledge about what the ritual is supposed to represent (which includes the ritual's origins) and seeing the ritual as the very objects represented in it (which includes the ritual's meaning in its present form). Therefore, there is no reason to reject the claim that the meaning of most rituals is to be elucidated by reference to their origins, if this claim pertains to knowledge of what the practice is supposed to represent. In this sense, Mass does not have a meaning independently of how the practice was developed. However, Wittgenstein is not discussing our knowledge of such a meaning, but a direct perception of meanings from the material available to us: we see the practice in a value-laden way rather than apprehend pieces of information about the practice that happen to include the fact that the practice has a meaning (which might require a causal-hypothetical explanation in terms of its origins). ${ }^{16}$

\footnotetext{
${ }^{15}$ Baker and Hacker (2005: 320-321), who make an analogy between Wittgenstein's remarks on Frazer and his views on aesthetics vis-à-vis the methodological error of using causal explanations, argue that "because ritual is symbolic," a surveyable representation "can resolve certain forms of perplexity where a developmental hypothesis cannot."

${ }^{16}$ These observations are tied to Wittgenstein's anti-scientism (e.g., CV 7e, 64e, 69e, 70e), which questions both the epistemological assumption that all knowledge must be scientific knowledge and the methodological assumption that the scientific method is the only way to gain knowledge (Beale 2017: 63). The flip side of Wittgenstein's anti-scientism is his emphasis on "preserving the integrity of a non-scientific form of understanding" (Monk 2005: 101). I am essentially arguing that skepticism about the relevance of the scientific method cannot explain why causal-hypothetical
} 
It is important to emphasize that there is nothing odd or mysterious about the meanings that constitute the "inner nature" of a practice, which brings us to the second aforementioned question about Wittgenstein's understanding of rituals. In particular, the inner nature of a practice-its meaning or meanings - is not a product of the practice when considered independently of our own psychological reactions. Accordingly, one can perceive the ritual's inner nature only if one is in possession of certain sensibilities that partially constitute the value-laden features in question and that make one susceptible to recognizing them. These sensibilities are not limited to a certain culture or era; rather, they are possessed by those people who share a certain form of life. Therefore, one should see the Beltane Festival "through the thoughts of man and his past, through all the strange things [one] see[s], and [has] seen and heard about, in [one]self and others" (GB 151). They include

a man's shadow, which looks like him, or his mirror-image, the rain, thunderstorms, the phases of the moon, the changing of the seasons, the way in which animals are similar to and different from one another and in relation to man, the phenomena of death, birth, and sexual life, in short, everything we observe around us year in and year out, interconnected in so many different ways, [which] will play a part in his thinking (his philosophy) and in his practices, or is precisely what we really know and find interesting. [GB 127-9]

However, since we also see "the inner nature of the modern practice itself," Wittgenstein's conceptualization of the nature of rituals offers a middle ground between understanding rituals in Humean-empiricist terms and understanding them in Platonic-realist terms: on the one hand, the inner nature of the festival is not a mere projection on our part onto a meaningless practice; on the other hand, there are no self-standing sources of significance that exist in the practice independently of our responses or the responses of participants in the practice. Rather than being

explanations are irrelevant for understanding rituals and aesthetics; rather, it is Wittgenstein's skepticism about the relevance of scientific knowledge in these contexts that provides the explanation. Furthermore, our understanding of the "non-scientific form of understanding" can be enriched by conceptualizing it as a form of aspect-perception. 
either entirely constituted by our psychological reactions or entirely dissociated from them, the value-laden phenomena in question are embedded in the normative existence of human life, of meanings that are part and parcel of "the tapestry of life" in general and of our being "a ceremonial animal" in particular (PPF §2 \& GB 129).${ }^{17}$ And what role does a surveyable representation play? The preferred interpretation should be, I believe, the "Neglected Aspects Model," in the sense that the proposed methodology is intended to dispel confusion by bringing a ritual into connection with pertinent phenomena, but with an important clarification: the subjective dimension, which pertains to our feelings and thoughts, cannot constitute the phenomena in question in their entirety, nor, indeed, should these phenomena be reduced to mere psychological reactions. Rather, perceiving "internal relations" and "formal connections" is crucial: while seeing the inner nature of a practice is an experience, it is an experience of seeing internal relations and formal connections between the practice and other practices and aspects of human life, so that certain features of the practice are thereby exhibited. ${ }^{18}$

\section{Conclusion: What Should the Anthropologist Do?}

I have argued that a surveyable representation of certain (broadly construed) anthropological facts allows us to see internal relations and formal connections, so that the inner nature of a ritual is exhibited, in much the same way that such a representation of aesthetic facts allows us to see the solution of an aesthetic puzzle. This form of seeing, which is taken from Wittgenstein's discussion

\footnotetext{
${ }^{17}$ Clack (1999: 148-54) suggests that Wittgenstein's intention is both to argue that the sinister quality of the festival is the result of those people taking part in it and to point to the fact that we have inherited these violent propensities. While I generally agree with these observations, it is worth emphasizing that the sinister meaning of the ritual should not be reduced to mere non-normative psychological reactions, either in those people taking part in it, or in us.

18 When presenting his Neglected Aspects Model, Baker (2004: 35) clearly has Wittgenstein's discussion of aspectperception in mind, as he discusses, among other things, the duck-rabbit diagram.
} 
of aspect-perception, both explains Wittgenstein's insistence that knowledge of the origins of a practice is not relevant to appreciating its "inner nature" and clarifies what is perceived when we perceive this "inner nature." Whatever the extent of Wittgenstein's true interest in anthropology, ${ }^{19}$ and while my aim in this paper has been primarily interpretative, I wish to conclude by noting the upshots of this discussion for anthropology (above and beyond the correction of misrepresentations of Wittgenstein's position by anthropologists ${ }^{20}$ ). The anthropologist has a double role to play. First, she must conduct fieldwork in order to collect the relevant data and make pertinent comparisons between the ritual of interest and other rituals. After all, who is better suited than the anthropologist to make these comparisons, in the same way that a musicologist, or perhaps an ethnomusicologist, would be the most relevant person to make comparisons between different pieces by Brahms and between Brahms and Keller, to use Wittgenstein's example. In this regard, if we understand the "Neglected Aspects Model" along the lines suggested above, according to which the relevant comparison class is not merely our feelings and thoughts, there is no reason to assume, as Clack does, that comparisons that are the result of fieldwork ought to be ruled out. ${ }^{21}$ Second, the anthropologist should aim to perceive the relations and connections between these various rituals, thus "seeing a ritual as having this meaning," to paraphrase Wittgenstein. In this regard, she needs to develop an ability akin to a 'musical ear' (PPF §260), as Wittgenstein puts it when discussing

\footnotetext{
${ }^{19}$ In an introduction to Wittgenstein's remarks on Frazer, Rhees (1971: 18) writes that "clearly [Wittgenstein] is not discussing history or anthropology," but, rather, his interests are primarily in the "mythology of our language." I believe that Rhees is overstating the point, but I will not make the case for that claim in the current paper.

${ }^{20}$ Ginzburg (1991: 15-16) declares that he attempted to follow, but ultimately abandoned, Wittgenstein's method, since he "was dealing not with circles and ellipses [...], but with men and women. [...] Human history does not unfold in the world of ideas, but in the sub-lunar world in which individuals are irreversibly born, inflict or endure suffering and die." My discussion shows that this is a false dichotomy. Needham (1985: 169-170) argues that the meaning of a ritual is ascribed to the festival by its practitioners and that Wittgenstein is wrong in claiming that the character of a ritual is to be elicited from our own experience. My discussion shows that the meanings in question are not ascribed, in any straightforward sense, by either practitioner or spectator, but are rather part and parcel of the practice itself.

${ }^{21}$ When Wittgenstein claims that "one must only correctly piece together what one knows, without adding anything," I take him to mean not that no fieldwork is required, but rather that the anthropologist should aim to see "something that already lies open to view" and does not lie "beneath the surface," as he put it when presenting his meta-philosophy.
} 
aspect-perception. Using her imagination is crucial in this regard: "The concept of an aspect is related to the concept of imagination. In other words, the concept 'Now I see it as...' is related to 'Now I am imagining that'. Doesn't it take imagination to hear something as a variation on a particular theme? And yet one does perceive something in so hearing it” (PPF §254). ${ }^{22}$ Consider, in conclusion, the example — discussed, among other places, in Winch (1964: 323)—of some indigenous Australians carrying a stick or a stone that is treated as if it embodies the soul of its carrier; if it is lost, the carrier anoints himself as the dead are anointed. Winch argues that it is not hard to see the sense in this practice, if we remember that a lover in our society may carry about a picture of their beloved, which may symbolize for him their relationship. When the lover loses the picture he may feel guilty and ask the beloved for forgiveness, like the person who anoints himself when he "loses his soul." If the anthropologist sees these internal relations between the two rituals - and other related rituals, which will require fieldwork - she will understand, per Wittgenstein, "what it all means."23,24

\footnotetext{
${ }^{22}$ One can also finds hints of the importance of the imagination in Wittgenstein's remarks on Frazer, for example, in his suggestion that we could "invent" certain rituals (although even here he is careful to note that this is possible because the rituals have a "common spirit") (GB 151; see also GB 127). Furthermore, Wittgenstein's (perhaps unfair) claim that Frazer was unable "to conceive of a life different from that of the England of his time" (GB 125) might be interpreted as a criticism of Frazer not sufficiently utilizing his imagination when examining the rituals of interest. ${ }^{23}$ The anthropologist who comes closest to appreciating Wittgenstein's lessons is Wendy James. In her book The Ceremonial Animal (2003), she defends the importance of the anthropological imagination and builds on Wittgenstein's ideas in order to provide non-reductive explanations of the ceremonial character of human life. I am grateful to an anonymous referee for encouraging me to discuss the upshots of Wittgenstein's view for anthropology. ${ }^{24}$ I am grateful to Amichai Amit, Gilead Bar-Elli, Yemima Ben-Menahem, David Finkelstein, Nicholas Koziolek, and Michael Kremer for invaluable comments on various drafts of this paper. I would also like to thank audiences at the Hebrew University of Jerusalem, McMaster University, and the University of Chicago for their feedback. Finally, I would like to thank two anonymous referees for the Australasian Journal of Philosophy, whose excellent comments were of great help in improving the paper.
} 


\section{References and Abbreviation Key}

Wittgenstein: Works, Notes, Lectures, Letters, and Conversations

[AWL] Wittgenstein, L. 2001. Wittgenstein's Lectures, Cambridge, 1932-1935: From the Notes of Alice Ambrose and Margaret Macdonald, ed. A. Ambrose, New York: Prometheus Books.

[CV] Wittgenstein, L. 1998. Culture and Value (Revised Second Edition), ed. G. H. von Wright, trans. P. Winch, Malden, MA: Blackwell Publishing.

[GB] Wittgenstein, L. 1993. Remarks on Frazer's Golden Bough, in Philosophical Occasions 19121951, ed. J. Klagge and A. Nordmann, trans. J. Beversluis, Indianapolis: Hackett Publishing Company: 115-155.

[LC] Wittgenstein, L. 1967. Lectures \& Conversations on Aesthetics, Psychology and Religious Belief, ed. C. Barrett, Berkeley, CA: University of California Press.

[MWL I] Moore, G.E. 1962. Wittgenstein's Lectures in 1930-1933, in Philosophical Papers, New York: Collier Books: 247- 318.

[MWL II] Wittgenstein, L. 2016. Wittgenstein Lectures, Cambridge 1930-1933: From the Notes of G. E. Moore, ed. D. G. Stern, B. Rogers, and G. Citron, Cambridge, UK: Cambridge University Press.

[PG] Wittgenstein, L. 1974. Philosophical Grammar, ed. R. Rhees, trans. A. Kenny, Berkeley, CA: University of California Press.

[PI] Wittgenstein, L. 2009. Philosophical Investigations (Revised Fourth Edition), trans. G.E.M. Anscombe, P. M. S Hacker, and J. Schulte, Malden, MA: Wiley-Blackwell.

[PPF] Wittgenstein, L. 2009. Philosophy of Psychology - A Fragment, in Philosophical Investigations (Revised Fourth Edition), trans. G.E.M. Anscombe, P. M. S Hacker, and J. Schulte, Malden, MA: Wiley-Blackwell: 182-243.

[RPP I] Wittgenstein, L. 1980. Remarks on the Philosophy of Psychology (Volume 1), ed. G.E.M. Anscombe and G.H. von Wright, trans. G.E.M. Anscombe, Oxford: Basil Blackwell. 
[VW] Wittgenstein, L., and Waismann, F. 2003. The Voices of Wittgenstein: The Vienna Circle, ed. G. Baker, trans. G. Baker, M. Mackert, J. Connolly, and V. Politis, London: Routledge.

[WVC] Waismann, F. 1979. Wittgenstein and the Vienna Circle, ed. B. McGuinness, trans. J. Schulte and B. McGuinness, New York: Barnes \& Noble.

[Z] Wittgenstein, L. 1967. Zettel, ed. G.E.M. Anscombe and G.H. von Wright, trans G.E.M. Anscombe, Berkeley, CA: University of California Press.

\section{Secondary Literature and Other Sources}

Baker, G. P. 2004. Philosophical Investigations §122: Neglected Aspects, in Wittgenstein's Method: Neglected Aspects, ed. K. J. Morris, Malden, MA: Blackwell Publishing: 22-51.

Baker, G. P., and Hacker, P. M. S. 2005. Wittgenstein: Understanding and Meaning: Part I Essays (Second Edition), Malden, MA: Blackwell Publishing.

Bar-Elli, G. 2006. Wittgenstein on the Experience of Meaning and the Meaning of Music, Philosophical Investigations 29/3: 217-249.

Beale, J. 2017. Wittgenstein's Anti-Scientific Worldview, in Wittgenstein and Scientism, ed. J. Beale and I. J. Kidd, London: Routledge: 59-80.

Ben-Moshe, N. forthcoming. On Wittgenstein's Notion of a Surveyable Representation: The Case of Psychoanalysis, History of Philosophy Quarterly.

Cioffi, F. 1998a. Wittgenstein and Obscurantism, in Wittgenstein on Freud and Frazer, Cambridge, UK: Cambridge University Press: 183-205.

Cioffi, F. 1998b. Wittgenstein and the Fire-festivals, in Wittgenstein on Freud and Frazer, Cambridge, UK: Cambridge University Press: 80-106.

Cioffi, F. 1998c. Wittgenstein on Making Homeopathic Magic Clear, in Wittgenstein on Freud and Frazer, Cambridge, UK: Cambridge University Press: 155-182.

Clack, B. R. 1999. Wittgenstein, Frazer and Religion, Basingstoke, Hampshire: Palgrave. 
Clack, B. R. 2017. Wittgenstein and Anthropology, in A Companion to Wittgenstein, ed. H. J. Glock and J. Hyman, Chichester, West Sussex: Wiley Blackwell: 627-638.

Day, W. 2017. The Aesthetic Dimension of Wittgenstein's Later Writings, in Wittgenstein on Aesthetic Understanding, ed. G. L. Hagberg, Cham, Switzerland: Palgrave Macmillan: 3-29.

Frazer, J. G. 1994. The Golden Bough: A Study in Magic and Religion (A New Abridgement from the Second and Third Editions), ed. R. Fraser, Oxford: Oxford University Press.

Ginzburg, C. 1991. Ecstasies: Deciphering the Witches' Sabbath, trans. R. Rosenthal, Chicago: The University of Chicago Press.

Hacker, P. M. S. 2001. Developmental Hypotheses and Perspicuous Representations: Wittgenstein on Frazer's Golden Bough, in Wittgenstein: Connections and Controversies. Oxford: Oxford University Press: 74-97.

James, W. 2003. The Ceremonial Animal: A New Portrait of Anthropology, Oxford: Oxford University Press.

Kenny, A. 1982. Wittgenstein on the Nature of Philosophy, in Wittgenstein and His Times, ed. B. McGuinness, Chicago: The University of Chicago Press: 1-26.

Klagge, J. C. 2003. The Puzzle of Goethe's Influence on Wittgenstein, in Goethe and Wittgenstein: Seeing the World's Unity in Its Variety, ed. F. Breithaupt, R. Raatzsch and B. Kremberg, Frankfurt: Peter Lang: 19-26.

Margalit, A. 1992. Sense and Sensibility: Wittgenstein on The Golden Bough, Iyyun: The Jerusalem Philosophical Quarterly 41: 301-318.

Martin, C. G. 2016. Wittgenstein on Perspicuous Presentations and Grammatical Self-Knowledge, Nordic Wittgenstein Review 5/1: 79-108.

McGuinness, B. 2002. Freud and Wittgenstein, in Approaches to Wittgenstein: Collected Papers, London: Routledge: 224-235.

Monk, R. 2005. How to Read Wittgenstein, London: Granta Books. 
Mulhall, S. 1990. On Being in the World: Wittgenstein and Heidegger on Seeing Aspects, London: Routledge.

Needham, R. 1985. Exemplars, Berkeley, CA: University of California Press.

Rhees, R. 1971. Introductory Note to Remarks on Frazer's Golden Bough, The Human World 3: $18-28$.

Schroeder, S. 2010. A Tale of Two Problems: Wittgenstein's Discussion of Aspect Perception, in Mind, Method and Morality: Essays in Honour of Anthony Kenny, ed. J. Cottingham and P. M. S. Hacker, New York: Oxford University Press: 352-371.

Winch, P. 1964. Understanding a Primitive Society, American Philosophical Quarterly 1/4: 307324. 